J. Raptor Res. 44(2):154-156

(C) 2010 The Raptor Research Foundation, Inc.

\title{
Twig Used as a Tool by the Egyptian Vulture (NeOPHRON PERCNOPTERUS)
}

\author{
KeY WORDS: Egyptian Vulture; Neophron percnopterus; Bulgaria; tool use.
}

The Egyptian Vulture (Neophron percnopterus), one of few birds that use instruments to handle food (Boswall 1977, $1978,1983)$, throws stones with its bill to break the shells of Ostrich (Struthio camelus) eggs (van Lawick-Goodall and van Lawick 1966; Brown et al. 1982). Other forms of tool use have not been reported for this species. In this paper we report the first observations of Egyptian Vultures using twigs as tools for gathering wool used in nest building or maintenance.

This study was conducted in the Vratsa Mountains, in an area of about $450 \mathrm{~km}^{2}$ in the western portion of the Balkan Mountains, which make up the interior of the Balkan Peninsula in northwestern Bulgaria (Hammond Inc. 1982). Throughout these limestone mountains, there are cliffs with 100-500-m talus slopes, isolated karst summits, caves, and karst sinks. Shrubby vegetation predominates at these high elevations under a continental climate.

The population of Egyptian Vultures in the study area was small. Based on observations from an ongoing study (Stoyanova and Stefanov 1993), at the time of the observations reported below, between 5 and 16 pairs of Egyptian Vultures were known to YS and NS in the area. In addition, 5 to 8 vultures appeared to be transient throughout the breeding season. All observations were made by YS and NS using telescopes and binoculars, from March through August 1990.

Tool use by Egyptian Vultures was first observed on 13 March 1990, in a sheep enclosure near Peak Okoltchica in the eastern part of the range. During sheep shearing, six Egyptian Vultures circled above the shearing area, which was enclosed by a fence of thorny shrubs. After the shepherd and sheep had left, two vultures landed in the enclosure and picked up bits of discarded wool. Later, one vulture, holding a twig in its bill that had been taken from the enclosure fence, swept its head numerous times from side to side, capturing wool from inside the enclosure on the twig. After the vulture had raked the wool into rough heaps, the vultures carried the wool up to their nest.

On 7 June, following another session of shearing in the same enclosure, the vultures again gathered wool. This time two birds gathered wool with the help of twigs. Later, both birds landed on the roof of a building used by the shepherds, and one of the vultures, still holding a twig in its bill, entered the building through an open window. Thirty seconds later, it flew out and landed on the roof again, still holding the twig, which now had wool attached. The vultures then pulled the wool off the twig. The first vulture entered the building three more times, and each time exited holding the twig with freshly collected wool attached. Finally, both birds carried the wool to their nest.

To ascertain the regularity with which the vultures used twigs as a tool, we began to place wool in areas frequented by the vultures. We always distributed $3 \mathrm{~kg}$ of wool at 0700 $\mathrm{H}$ to approximately coincide with the timing of shearing, which began at $0730 \mathrm{H}$, and prior to when sheep were let out to graze at $0900 \mathrm{H}$. On 18 June, we scattered wool in the same enclosure where we had noticed the use of twigs on 13 March and 7 June. Seven vultures visited the area, but none landed. On 20 and 28 June, we placed wool at another sheep enclosure; six and eight vultures arrived on those dates, respectively, but none gathered wool.

On 3 July, we altered our approach. In a sheep enclosure near Peak Okoltchica, we placed wool in the enclosure in advance and the shepherds only simulated shearing of the sheep. When the sheep were then let out to graze, 12 vultures, which had arrived during the simulated shearing, landed in the enclosure and 11 began to pick up the scattered wool. Four of the vultures used twigs to gather the wool.

On 4 July, we again distributed wool in the enclosure but no actual or simulated shearing took place. Six vultures came but none collected wool. On 18 July, we scattered wool and had the shepherds simulate shearing. Nine vultures visited the enclosure and eight of them gathered wool but none used twigs. On 23 July and 5 August, we scattered wool at a sheepfold in the western Vratsa Mountains without shearing. Twelve and 14 vultures visited, respectively, but none gathered wool. On 8 August, simulated shearing was carried out at the same sheepfold and wool was scattered. Ten of the 11 vultures present gathered wool, including five vultures that used twigs. We repeated the activity at another 
sheepfold on 16 August and five vultures gathered wool with the help of twigs and four without. In some other cases, although wool was distributed, the vultures did not visit the enclosures: 19 June, and 10, 12 and 13 July.

In summary, in the $14 \mathrm{~d}$ of planned observations and $2 \mathrm{~d}$ before, YS and NS saw from 0 to 14 vultures per day, for a total of 102 vulture observations over $12 \mathrm{~d}$; vultures gathered wool without twigs 25 times on $5 \mathrm{~d}$, on 17 occasions on $5 \mathrm{~d}$ they gathered wool using twigs, and 60 additional observations of vultures did not involve wool-gathering on $10 \mathrm{~d}$. During the planned observations, gathering began 5 , 6,23 , and $150 \mathrm{~min}$ after sheep left the enclosure. Vultures gathered wool for 53 to $71 \mathrm{~min}$, and all vultures departed the sheep enclosure by 13:00 $\mathrm{H}$ each day.

Interestingly, some of the vultures gathered wool throughout the summer, including the nestling and fledging stages. It is possible that the wool also served to pad and insulate nestlings and not just eggs and the incubating adults. Furthermore, the wool could have been absorbent and thus served in nest hygiene. Finally, young vultures may have been involved in gathering wool and these birds may have "played" to improve the development of a complex behavioral trait.

Twigs are employed by some avian species as tools to obtain food: Woodpecker Finch (Camarhynchus pallidus), Mangrove Finch (C. heliobates), Varied Sittella (Daphoenositta chrysoptera), African Grey Flycatcher (Bradornis microrhynchus), and Green Jay (Cyanocorax yncas; Boswall 1977, $1978,1983)$. The use of an object as a tool can be difficult to discern when both the tool itself and its secondary purpose are useful to birds (e.g., Levey et al. 2004). Although a twig used to obtain food appears to be a good indicator of tool use, both twigs and wool are typically found in nests of Egyptian Vultures (e.g., Mundy et al. 1992) and both are useful as components of the nest.

Although tool-related bird behavior can appear goal-oriented, it may be incidental (e.g., Griffin 2001). Heinrich (1988) concluded that the dropping of stones on intruders by Common Ravens (Corvus corax) was more likely out of "frustration" or a displacement behavior. Similarly, Schmutz (1992) concluded that the dropping of prey near intruders by nesting Ferruginous Hawks (Buteo regalis) was likely incidental. In the case of the vultures studied here, it is conceivable that twig use originated firstly from the gathering of twigs per se for nest building and that wool adhered accidentally. However, the context of the observations made by YS and NS seem to indicate an intentional use of twigs as a tool: (1) a vulture interrupted wool- gathering, picked up a stick, and then resumed wool-gathering, (2) multiple entries by a vulture into a building with a clean twig that was covered with wool on the bird's departure from the building, and then stripped of wool before the next entry, and (3) the persistent use of twigs followed by the twigs being discarded. Although it is likely that the vultures were able to gather wool more efficiently with twigs, YS and NS did not record the relative amounts collected with or without twigs, or the collection time involved.
Tool use appeared to be relatively common in this study, but YS and NS found that not all vultures practiced it all of the time. Although vultures in two parts of the study area used twigs, the behavior has not been reported from other parts of the species' range. When tool-use is exhibited by a bird species, often it is observed sporadically throughout a population (e.g., Marks and Hall 1992). Egyptian Vultures are known to line their nests with animal fur and twigs (Mundy et al. 1992) and this association of nesting materials may have facilitated learning that wool (including that left by shepherds after shearing operations) could be gathered with the use of a twig.

The manuscript was improved by comments kindly provided by Maurizio Sarà, Grant Stevenson, and two anonymous referees.-Yva Stoyanova, ${ }^{1}$ and Nikolai Stefanov, ${ }^{1}$ Blvd. Nikola Voivodov 19, Vratsa 3000, Bulgaria; José A. Donázar, Departmento de Biología Applicada, Estación Biológica de Doñana-CSIC, Avenida Maria Luisa s/n, 41013 Sevilla, Spain; Josef K. Schmutz (email address: joe.schmutz@usask.ca), School of Environment and Sustainability, University of Saskatchewan, 117 Science Place, Saskatoon, SK, S7N 5C8, Canada.

\section{Literature Cited}

Boswall, J. 1977. Tool-using by birds and related behavior. Avicultural Magazine 83:88-97, 146-159, 220-228.

1978. Further notes on tool-using behavior by birds and related behavior. Avicultural Magazine 84: 162-166.

- 1983. Tool-using and related behavior in birds, more notes. Avicultural Magazine 89:94-108, 170-181.

Brown, L.H., E.K. Urban, AND K. NEWMAN. 1982. The birds of Africa, Vol. 1. Academic Press, London, U.K.

GRIFFIN, D.R. 2001. Animal minds: beyond cognition to consciousness. University of Chicago Press, Chicago, IL U.S.A.

HAMmOND INC. 1982. Hammond world atlas. Hammond, Inc., Maplewood, NJ U.S.A.

HeinRich, B. 1988. Raven tool use. Condor 90:270-271.

Levey, D.J., R.S. Duncan, And C.S. Levins. 2004. Use of dung as a tool by Burrowing Owls. Nature 431:39.

Marks, J.S. AND C.S. HALl. 1992. Tool use by Bristlethighed Curlews feeding on albatross eggs. Condor 94:1032-1034.

Mundy, P., D. Butchart, J. Ledger, And S. Piper. 1992. The vultures of Africa. Academic Press, London, U.K.

${ }^{1}$ Editor's Note: An earlier version of this manuscript was circulated by Yva Stoyanova and Nikolai Stefanov for input and possible future publication in The Journal of Raptor Research. Tragically, both Yva and Nikolai died in a traffic accident on 14 January, 1993. To capture these interesting observations in the ornithological literature, José A. Donázar and Josef K. Schmutz reviewed and revised the manuscript, and submitted it. 
SchmuTZ, J.K. 1992. Should single observations be published? Journal of Raptor Research 26:99.

Stoyanova, Y. And N. Stefanov. 1993. Predation upon nestling Egyptian Vultures (Neophron percnopterus) in the Vratsa Mountains of Bulgaria. Journal of Raptor Research 27:123.
VAN LAWICK-GOODALL, J. AND H. VAN LAWICK 1966. Use of tools by Egyptian Vulture Neophron percnopterus. Nature 212:1468-1469.

Received 23 March 2009; accepted 16 November 2009 Associate Editor: Joseph B. Buchanan 